\title{
Mechanochemical synthesis of cerium(IV)-phosphonates
}

Manuel Wilke ${ }^{a}$, Irina Akhmetova ${ }^{b}$, Klaus Rademannc, and Franziska Emmerling ${ }^{b^{*}}$

a Swiss Light Source, Material Science Beamline, Paul Scherrer Institute, 5232 Villigen PSI, Switzerland

b BAM Federal Institute for Materials Research and Testing, Richard-Willstätter-Straße 11, 12489 Berlin, Germany

c Department of Chemistry, Humboldt-Universität zu Berlin, Brook-Taylor-Str. 2, 12489 Berlin, Germany

E-mails: $\quad$ manuel.wilke@psi.ch

irina.akhmetova@bam.de

klaus.rademann@chemie.hu-berlin.de

franziska.emmerling@bam.de

* Fax: +49 308104 1137; Tel: +49 3081041133

\section{Abstract}

The syntheses and crystal structures of two cerium(IV) phosphonates are presented. Cerium(IV) bis(phenylphosphonate) $\mathrm{Ce}\left(\mathrm{O}_{3} \mathrm{PC}_{6} \mathrm{H}_{5}\right)_{2} 1$ can be formed from precipitation and mechanochemical reaction, whereas cerium(IV) bis(carboxymethylphosphonate) monohydrate $\mathrm{Ce}\left(\mathrm{O}_{3} \mathrm{PCH}_{2} \mathrm{COOH}\right)_{2} \cdot \mathrm{H}_{2} \mathrm{O}$ $\mathbf{2}$ is only accessible via ball milling. All reactions proceed very fast and are completed within a short time span. In situ measurements for the syntheses of 1 show that the product occurs within seconds or a few minutes, respectively. The structures were solved from powder X-ray diffraction (PXRD) data.

\section{Keywords}

Mechanochemistry, in situ, PXRD, cerium(IV), metal phosphonate

This document is the accepted manuscript version of the following article:

wilke, M., Akhmetova, I., Rademann, K., \& Emmerling, F. (2018). Mechanochemical synthesis of cerium(IV)-phosphonates. Journal of Materials Science, 53(19), 13733-13741.

https: //doi .org/10.1007/s10853-018-2507-x 


\section{Introduction}

The synthesis and characterization of metal phosphonates has gained increasing interest because of their promising properties for applications like gas adsorption [1-3], catalysis [3-5], proton conduction [6-10], corrosion protection [11], or magnetic cooling [12, 13]. The phosphonate ligand offers a wide range of possible coordination modes, therefore metal phosphonates exhibit variable structure motifs, from molecular compounds (OD) to 3D frameworks [12, 14, 15]. This structural variety makes metal phosphonates promising candidates for application-tuned materials. New synthesis methods like high-throughput hydrothermal methods [16, 17] or ultrasonic synthesis [18] were developed. Recently, we could show that divalent metal phosphonates of different dimensionality can easily be synthesized mechanochemically [19-22]. The mechanisms of mechanochemical reactions are not completely understood yet. Therefore, several methods have been developed enabling in situ monitoring of the milling process [23-25]. Although tetravalent metal phosphonates are widely studied [26-29], only a few cerium(IV) phosphonates are known so far [30-32]. One reason is the high potential of cerium(IV) to act as oxidizing agent. Since Ce(IV) is able to oxidize water, the formation of $\mathrm{Ce}$ (III) phosphonates is typically observed in hydrothermal reactions [33].

Here, we present the synthesis of two cerium(IV) phosphonates, namely cerium(IV) bis(phenylphosphonate) $\quad \mathrm{Ce}\left(\mathrm{O}_{3} \mathrm{PC}_{6} \mathrm{H}_{5}\right)_{2} \quad 1$ and cerium(IV) bis(carboxymethylphosphonate) monohydrate $\mathrm{Ce}\left(\mathrm{O}_{3} \mathrm{PCH}_{2} \mathrm{COOH}\right)_{2} \cdot \mathrm{H}_{2} \mathrm{O} 2$ (Fig. 1). Compound 1 was synthesized from solution at room temperature and from mechanochemical synthesis using ceric ammonium nitrate (CAN, diammonium cerium(IV) nitrate) and phenylphosphonic acid. Compound $\mathbf{2}$ was synthesized via a liquid assisted grinding (LAG) reaction with CAN and phosphonoacetic acid. The structures were solved from PXRD (powder X-ray diffraction) data. Both syntheses of 1 were investigated in situ using synchrotron PXRD.
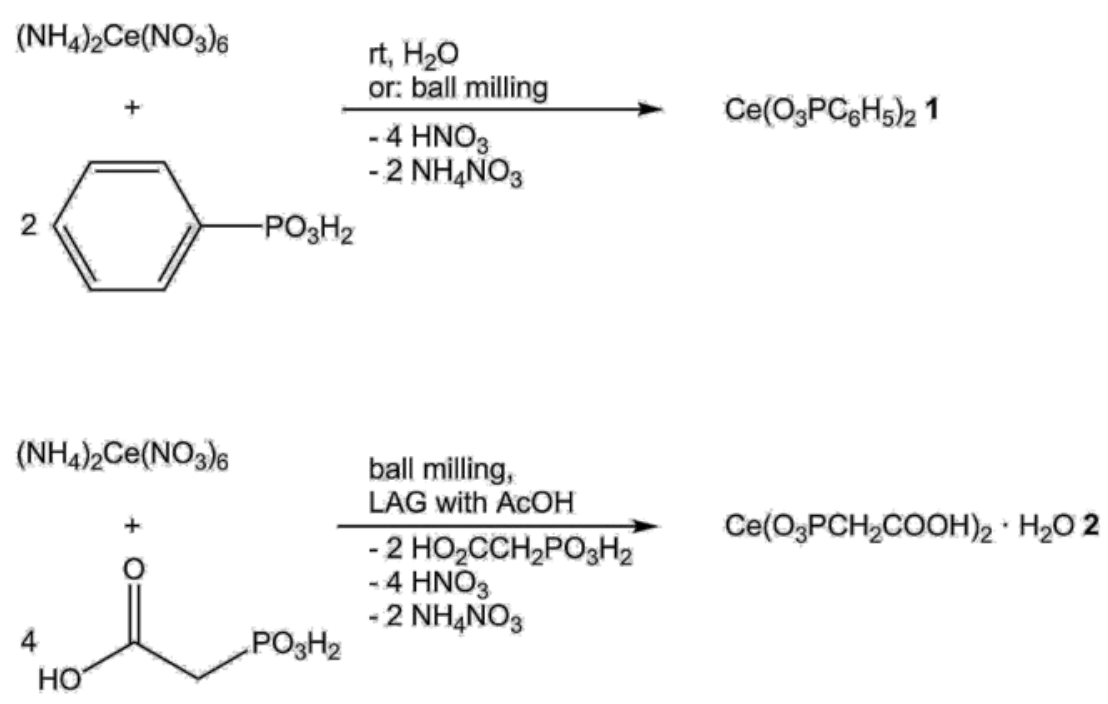

Figure 1 Reaction schemes for the synthesis of $\mathrm{Ce}\left(\mathrm{O}_{3} \mathrm{PC}_{6} \mathrm{H}_{5}\right)_{2} \mathrm{I}$ and $\mathrm{Ce}\left(\mathrm{O}_{3} \mathrm{PCH}_{2} \mathrm{COOH}\right)_{2} \cdot \mathrm{H}_{2} \mathrm{O} 2$.

\section{Materials and Methods}

\section{Chemicals}


The following chemicals were used without further purification: Ceric ammonium nitrate ( $\geq 98 \%$, reinst, Roth, Germany) phenylphosphonic acid (98\%, Acros Organics, USA), phosphonoacetic acid (98\%, abcr, Germany), methanol (99.8+\%, Acros Organics, USA), glacial acetic acid (100\%, p. a., Roth, Germany), and MilliQ water (18.2 M $\Omega$, ultrapure water system seralpur Pro $90 \mathrm{CN}$, Seral, Germany).

\section{Synthesis of $\mathrm{Ce}\left(\mathrm{O}_{3} \mathrm{PC}_{6} \mathrm{H}_{5}\right)_{2} 1$}

Synthesis from solution: $1097.0 \mathrm{mg}(2.00 \mathrm{mmol})$ of ceric ammonium nitrate and $632.0 \mathrm{mg}$ $(4.00 \mathrm{mmol})$ of phenylphosphonic acid were dissolved in $30 \mathrm{~mL}$ of water, respectively. The clear solutions were mixed and an immediate precipitation could be observed. The reaction mixture was stirred at room temperature for $5 \mathrm{~min}$. The precipitate was separated by filtration, washed with water and dried in air. $820 \mathrm{mg}(1.8 \mathrm{mmol})$ of a pale yellow powder was obtained (yield $=91 \%)$.

Mechanochemical synthesis: For the mechanochemical synthesis a vibration ball mill Pulverisette 23 (Fritsch $\mathrm{GmbH}$, Germany) was used. Ceric ammonium nitrate and phenylphosphonic acid were added in a $10 \mathrm{~mL}$ steel jar with a total load of $1 \mathrm{~g}$ and a molar ratio of 1:2. Two stainless steel balls (diameter $=10 \mathrm{~mm}$, weight $=4 \mathrm{~g}$ ) were added. This mixture was ground at $50 \mathrm{~Hz}$ for $15 \mathrm{~min}$. A yellow powder was obtained, washed with methanol and dried in air. $339.7 \mathrm{mg}(0.75 \mathrm{mmol})$ of a pale yellow powder were obtained (yield $=65 \%$ ). The synthesis was repeated with an addition of $400 \mu \mathrm{L}$ of water which results in a slightly more crystalline product.

\section{Synthesis of $\mathrm{Ce}\left(\mathrm{O}_{3} \mathrm{PCH}_{2} \mathrm{COOH}\right)_{2} \cdot \mathrm{H}_{2} \mathrm{O} 2$}

The synthesis procedure was similar to the mechanochemical synthesis of $\mathbf{1}$ except that phosphonoacetic acid was used and that the ratio of ceric ammonium nitrate to phosphonoacetic acid was 1:4. To obtain a product with a good crystallinity, the addition of $400 \mu \mathrm{L}$ acetic acid was necessary. The wet product was washed with methanol and dried in air. $264.6 \mathrm{mg}(0.61 \mathrm{mmol})$ of a pale yellow powder were obtained (yield $=68 \%$ ).

\section{Analytical techniques}

PXRD patterns were collected on a D8 Discover diffractometer (Bruker AXS, Germany) with Cu K $\alpha 1$ radiation $(\lambda=0.154056 \mathrm{~nm}$ ). The diffractometer is equipped with a Lynxeye detector and a Johansson monochromator in the incident beam. Measurements were performed in transmission geometry in a $2 \theta$ range from $4^{\circ}$ to $60^{\circ}$. For structure solution a step size of $0.009^{\circ}$ with a measured time per step of $25 \mathrm{~s}$ was chosen. The structure solutions of all compounds were conducted from PXRD data. The crystal data of $\mathbf{1}$ and $\mathbf{2}$ were indexed using the indexing routine in Topas (version 5, Bruker AXS, 2014). The crystal structures were determined using the simulated annealing routine implemented in DASH [34]. For 1 the Ce atom was fixed at the Wyckoff position 2a $(0, y, 0)$. Rietveld refinements were conducted with Topas. CCDC-1824013 and CCDC-1824014 contain the supplementary crystallographic data for $\mathbf{1}$ and $\mathbf{2}$. These data can be obtained free of charge from the Cambridge Crystallographic Data Centre via www.cdc.cam.ac.uk/data_request/cif.

The in situ PXRD measurements were performed at the $\mu$ Spot beamline (Bessy II, Helmholtz-Zentrum Berlin, Germany) [34]. For data collection, a MarMosaic CCD detector (pixel size: 3072 × 3072, point spread function width: $73 \mu \mathrm{m}$ ) was used. The exposure time was $30 \mathrm{~s}$, with a delay time of 3-4 s between two measurements. For the direct comparison with the laboratory PXRD data, the 
scattering vector $\mathrm{q}$ was transformed to the diffraction angle $2 \theta$ for $\mathrm{Cu} \mathrm{K}_{\alpha 1}$ radiation using FIT2D [35]. All given times are rounded to the nearest $15 \mathrm{~s}$.

The setup used for the investigation of the precipitation reaction was described in detail elsewhere [36]. In brief, the stopped-flow-module SFM-3000 (Bio-Logic SAS, France) equipped with a capillary head and a custom-made extension was used. The starting solutions were loaded to two inner syringes. For the measurements, the starting solutions were mixed and the reaction solution was pushed through the capillary head and the custom-made extension. By varying the flow rate and the position of the measurement (capillary head or extension), different points in time could be investigated. Every point in time was measured three times and the resulting patterns were accumulated.

The in situ investigation of mechanochemical reactions with synchrotron radiation was described elsewhere [20]. The reactions were conducted as described above, except that the steel jar was replaced with a Perspex jar.

\section{Results}

\section{Synthesis and structure}

The final Rietveld and difference plots of $\mathbf{1}$ and $\mathbf{2}$ (Fig. 2) proof the purity of the obtained compounds. The crystal data and figure of merits of both compounds are shown in Table 1. Selected bond lengths and angles of all new compounds are given in Table S1 and S2.

Table 1: Crystal data and structure refinement parameters for $\mathrm{Ce}\left(\mathrm{O}_{3} \mathrm{PC}_{6} \mathrm{H}_{5}\right)_{2} 1$ and $\mathrm{Ce}\left(\mathrm{O}_{3} \mathrm{PCH}_{2} \mathrm{COOH}\right)_{2}$ - $\mathrm{H}_{2} \mathrm{O}$ 2. $\mathrm{R}$ values refer to the Rietveld criteria of fit for profile, weighted profile, and structure factor, as defined by Langford and Louer [35].

\begin{tabular}{|c|c|c|}
\hline & 1 & 2 \\
\hline Empirical formula & $\mathrm{CeC}_{12} \mathrm{H}_{10} \mathrm{O}_{6} \mathrm{P}_{2}$ & $\mathrm{CeC}_{4} \mathrm{H}_{8} \mathrm{O}_{11} \mathrm{P}_{2}$ \\
\hline Formula weight/g mol-1 & 452.27 & 434.16 \\
\hline Crystal system & monoclinic & monoclinic \\
\hline Space group & C2 (No. 5) & $\mathrm{P} 2_{1} / \mathrm{a}$ (No. 11) \\
\hline $\mathrm{a} / \AA ̊$ & $9.4040(3)$ & $21.3543(5)$ \\
\hline $\mathrm{b} / \AA ̊$ & $5.6454(2)$ & $9.8053(3)$ \\
\hline$c / \AA ̊$ & $14.9146(5)$ & $5.1358(2)$ \\
\hline$\beta /^{\circ}$ & $83.352(4)$ & $90.731(3)$ \\
\hline $\mathrm{V} / \AA^{3}$ & $786.48(4)$ & $1075.27(5)$ \\
\hline Z & 2 & 4 \\
\hline $\mathrm{D}_{\text {calc }} / \mathrm{g} \mathrm{cm}^{-3}$ & 1.910 & 2.682 \\
\hline $\mathrm{R}_{\mathrm{wp}}$ & 1.71 & 3.59 \\
\hline $\mathrm{R}_{\text {Bragg }}$ & 0.88 & 1.89 \\
\hline GOF & 1.56 & 2.19 \\
\hline
\end{tabular}



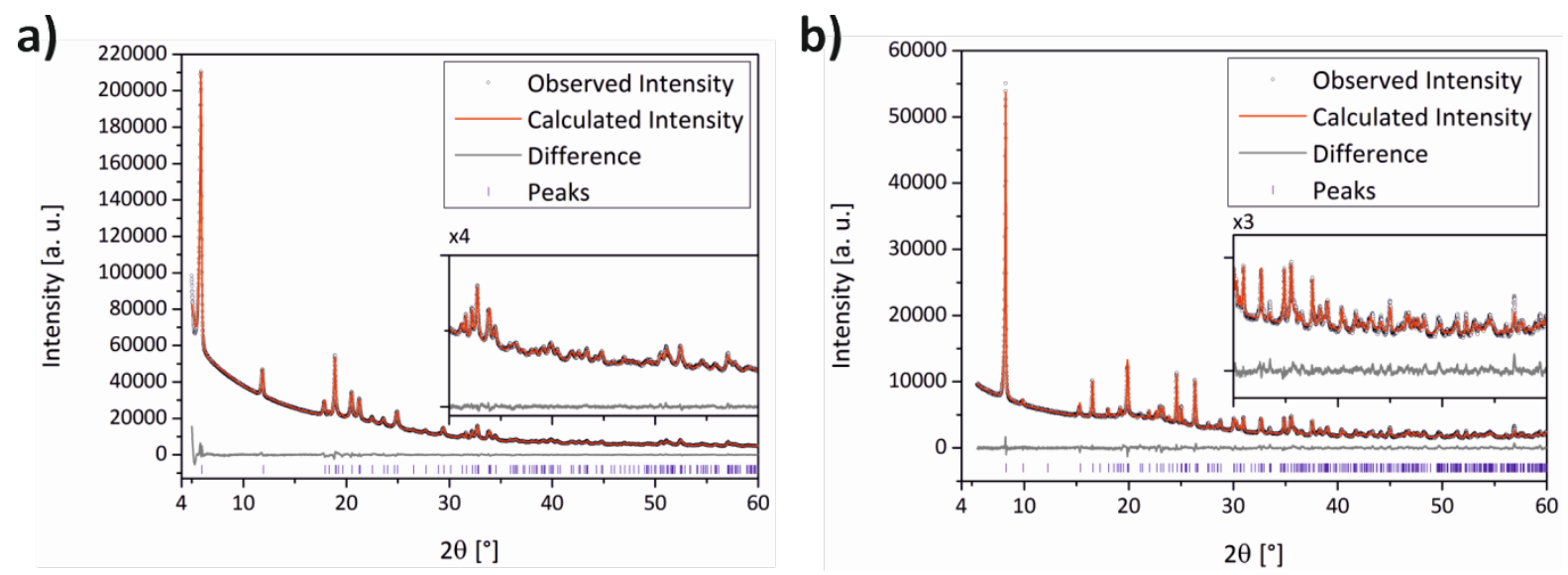

Figure 2 Scattered intensity of a) $\mathrm{Ce}\left(\mathrm{O}_{3} \mathrm{PC}_{6} \mathrm{H}_{5}\right)_{2} \mathbf{1}$ and b) $\mathrm{Ce}\left(\mathrm{O}_{3} \mathrm{PCH}_{2} \mathrm{COOH}\right)_{2} \cdot \mathrm{H}_{2} \mathrm{O} 2$ under ambient conditions as a function of the diffraction angle $2 \theta$. The observed pattern (circles), the best Rietveld fit profile (red line), the reflection positions (blue tick marks), and the difference curve (grey line) between the observed and calculated profiles are shown. The wavelength is $\lambda=0.154056 \mathrm{~nm}$ (Cu $\left.\mathrm{K}_{\alpha 1}\right)$.

The structure of $\mathbf{1}$ is depicted in Fig. 3. The Ce ${ }^{4+}$-ion is coordinated by six oxygen atoms, from six different phenylphosphonate ligands, in a slightly distorted octahedron. The $\mathrm{Ce}-\mathrm{O}$ bond lengths range from 2.105(6) $\AA$ to 2.223(1) $\AA$ and the O-Ce-O angles from $84.8(4)^{\circ}$ to $94.2(4)^{\circ}$. Each oxygen atom of each phosphonate group is coordinating to one $\mathrm{Ce}^{4+}$-ion. The $\mathrm{CeO}_{6}$-octahedra are connected via the phosphonate group, leading to the typical layered structure motif for metal phosphonates: The $\mathrm{Ce}^{4+}-$ ion and the coordinating phosphonate groups are forming an inorganic layer while the phenyl rings point into the interlayer space. The layers are connected via van der Waals forces between the phenyl rings.

a)

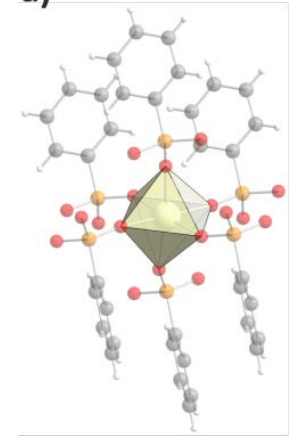

b)

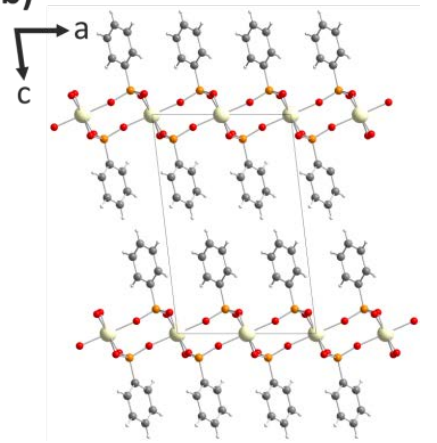

Figure 3 a) Molecular structure of $\mathrm{Ce}\left(\mathrm{O}_{3} \mathrm{PC}_{6} \mathrm{H}_{5}\right)_{2} 1$ with coordination polyhedron for the $\mathrm{Ce}^{4+}$-ion and b) crystal structure of $\mathbf{1}$ shown along the b-axis. Pale yellow: cerium, orange: phosphorus, red: oxygen, grey: carbon, light grey: hydrogen.

The structure of $\mathbf{2}$ is shown in Fig. $\mathbf{4}$. The $\mathrm{Ce}^{4+}$-ion is coordinated by seven oxygen atoms in a capped octahedron. The oxygen atoms stem from six different carboxymethylphosphonate ligands and one water molecule. The Ce-O bond lengths differ from 2.08(1) A to 2.34(1) A. All oxygen atoms of the phosphonate groups and the water molecule are coordinating to one $\mathrm{Ce}^{4+}$-ion. The $\mathrm{CeO}_{7}$-units are connected via the phosphonate group. A layered structure as in $\mathbf{1}$ is formed, except that the layers are connected via hydrogen bonds between the carboxylic groups $\left(d_{04-05}=2.63(2) \AA\right.$ ). 


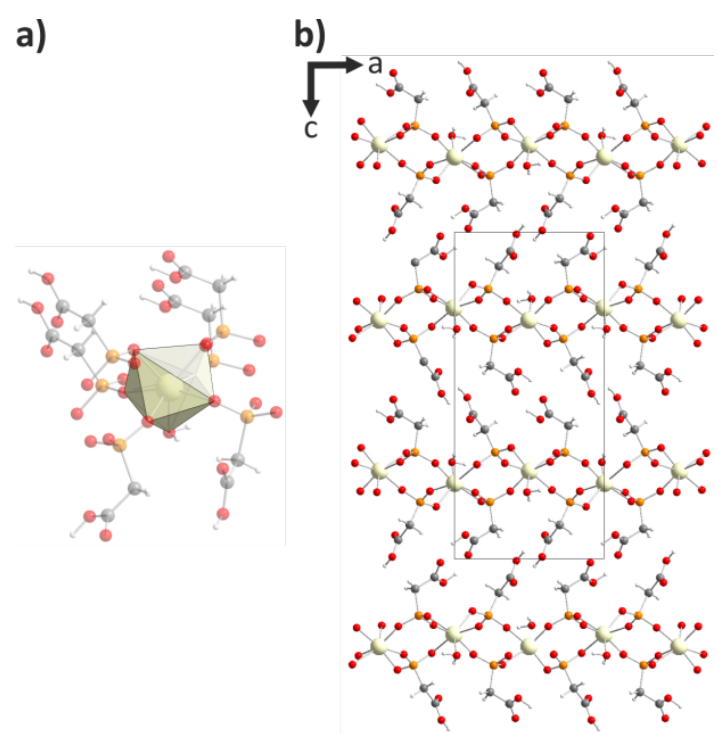

Figure 4: a) Molecular structure of $\mathrm{Ce}\left(\mathrm{O}_{3} \mathrm{PCH}_{2} \mathrm{COOH}\right)_{2} \cdot \mathrm{H}_{2} \mathrm{O} 2$ with coordination polyhedron for the $\mathrm{Ce}^{4+}$-ion in and $\left.\mathbf{b}\right)$ crystal structure of $\mathbf{2}$ shown along the b-axis. Pale yellow: cerium, orange: phosphorus, red: oxygen, grey: carbon, light grey: hydrogen.

\section{Mechanistic studies}

The syntheses of 1 from solution and as mechanochemical reaction were studied in situ. Fig. $\mathbf{5}$ shows the powder patterns of the in situ investigation of the precipitation reaction. Already in the first pattern after $0.33 \mathrm{~s}$, a reflection at $5.9^{\circ}$ is proving the formation of the final product 1 . Additional reflections at $8.0^{\circ}$ and $11.1^{\circ}$ cannot be assigned to any starting material or the product. An intermediate is formed. After $0.66 \mathrm{~s}$, only the reflection for 1 remains. Its intensity increases during the next ten seconds, but no other reflections appear.
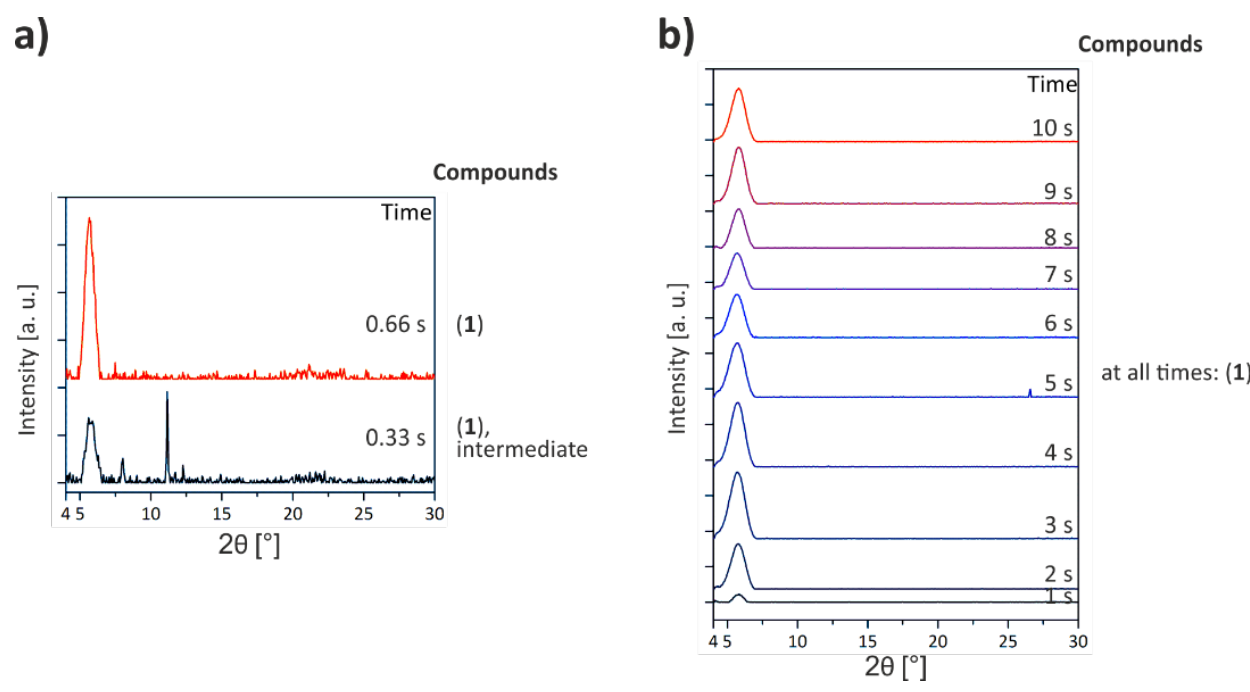

Figure 5: Powder patterns of the in situ studies of the synthesis from solution of $\mathrm{Ce}\left(\mathrm{O}_{3} \mathrm{PC}_{6} \mathrm{H}_{5}\right)_{2}$ 1: a) for the measurements of the reaction points in time $0.33 \mathrm{~s}$ and $0.66 \mathrm{~s}$ and $\mathbf{b}$ ) for the measurements of the reaction points in time $1 \mathrm{~s}$ to $10 \mathrm{~s}$. 
The 2D plots of the in situ investigations of the mechanochemical syntheses of $\mathbf{1}$ are depicted in Fig. 6. The results for the neat grinding synthesis are shown in Fig. 6a. At the beginning only reflections for the starting materials are present (step 1). After $3.30 \mathrm{~min}$, a reflection at $5.9^{\circ}$ shows the formation of the final product 1 (step 2). The intensity of the reflections of the starting materials is decreasing but they remain until the end. After $10.30 \mathrm{~min}$, additional reflections at $17.9^{\circ}, 22.4^{\circ}$ and $28.9^{\circ}$ prove the formation of ammonium nitrate as side product (step 3). With the addition of water to the grinding material the reaction pathway changes massively. The respective $2 \mathrm{D}$ plot is shown in Figure $\mathbf{6 b}$. At the beginning, no reflections, not even of the starting materials, can be detected. After $30 \mathrm{~s}$, two reflections at $7.7^{\circ}$ and $8.9^{\circ}$ show the formation of an unknown intermediate (step 2). After $1.15 \mathrm{~min}$, the formation of $\mathbf{1}$ is evident by the reflection at $5.9^{\circ}$. The product and the intermediate remain side by side until after $3.30 \mathrm{~min}$ the reflections of the intermediate are vanished (step 3). For the next minutes, only reflections of 1 can be detected (step 4). After $7.00 \mathrm{~min}$, additional reflections show again the formation of ammonium nitrate as side product (step 5). The synthesis of $\mathrm{Ce}\left(\mathrm{O}_{3} \mathrm{PCH}_{2} \mathrm{COOH}\right)_{2} \cdot \mathrm{H}_{2} \mathrm{O} 2$ could not be investigated in situ since the perspex jar was not stable against the used chemicals.

a)

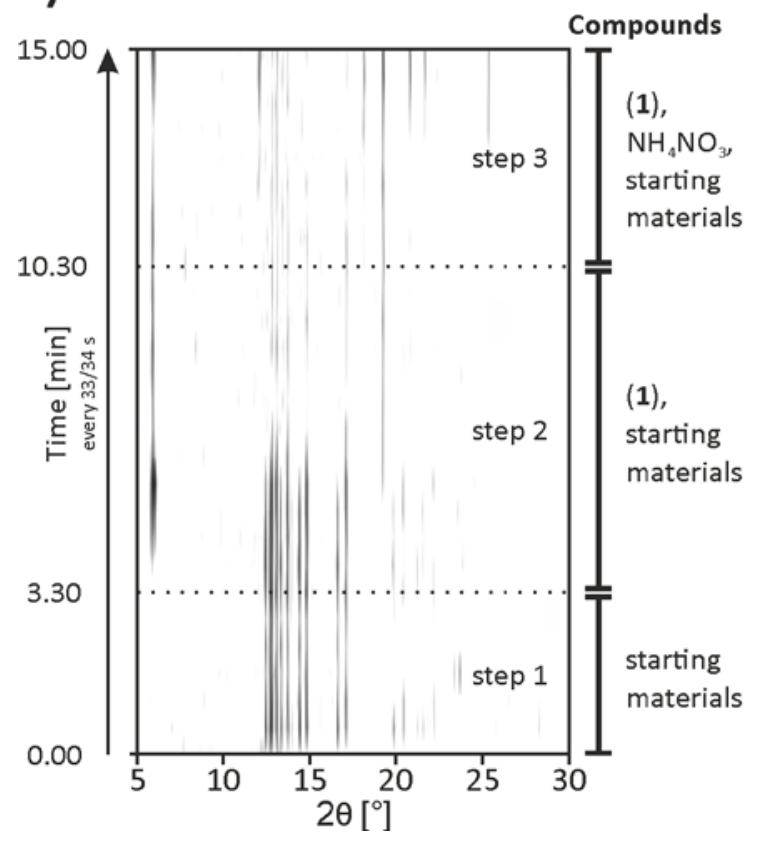

b)

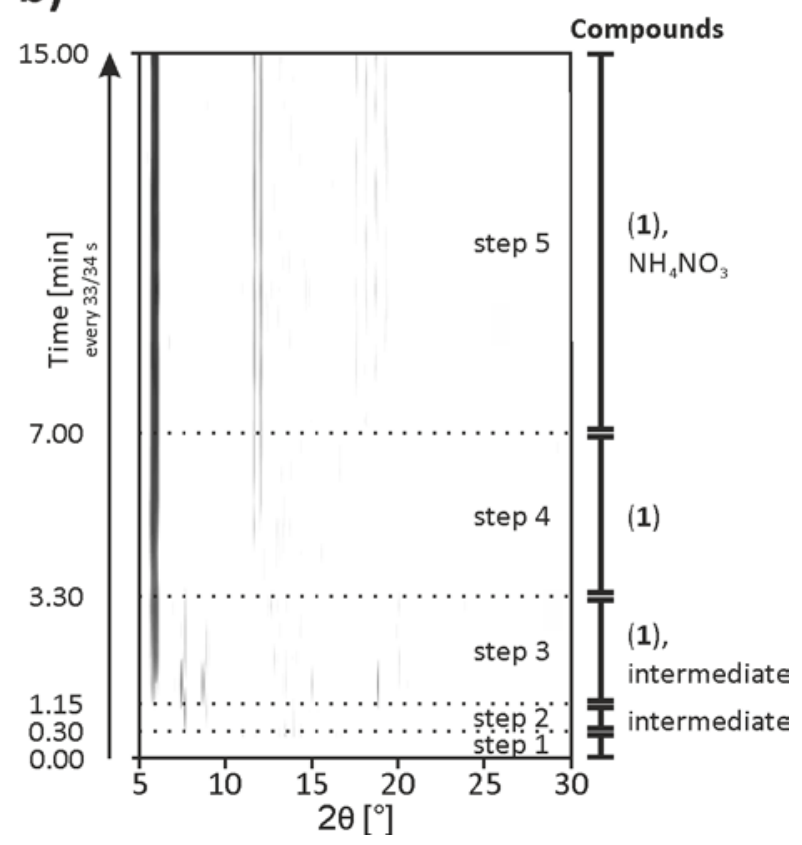

Figure 6: Powder patterns of the in situ studies of the mechanochemical syntheses of $\mathrm{Ce}\left(\mathrm{O}_{3} \mathrm{PC}_{6} \mathrm{H}_{5}\right)_{2} \mathbf{1}$ : a) neat at $50 \mathrm{~Hz}$ and $\mathbf{b}$ ) as LAG synthesis with water at $50 \mathrm{~Hz}$.

\section{Discussion}

Compound 1 was synthesized from precipitation reaction and mechanochemical reaction. The first product shows a slightly higher crystallinity (see Fig. S1). The syntheses can be described as follows:

$\left(\mathrm{NH}_{4}\right)_{2} \mathrm{Ce}\left(\mathrm{NO}_{3}\right)_{6}+2 \mathrm{H}_{2} \mathrm{O}_{3} \mathrm{PR} \rightarrow \mathrm{Ce}\left(\mathrm{O}_{3} \mathrm{PR}\right)_{2}+2 \mathrm{NH}_{4} \mathrm{NO}_{3}+4 \mathrm{HNO}_{3}$

$\left(\mathrm{R}=\mathrm{C}_{6} \mathrm{H}_{5}\right.$ for 1$)$.

Ammonium nitrate and nitric acid are formed as side products. To get the pure product in the mechanochemical synthesis, the product was washed with methanol. 
For 2, the reaction equation is basically the same (with $\mathrm{R}=\mathrm{CH}_{2} \mathrm{COOH}$ ) except for the following changes: For the hydrated compound, water is required. No water was added in the synthesis. Most probably, there is already surface water present or the hygroscopic side product ammonium nitrate attracts water from the environment. The use of an excess of phosphonoacetic acid and the addition of glacial acetic acid is necessary for a higher crystallinity. The addition of a strong acid increases the protonation degree of the phosphonic acid, which results in a slower reaction progress and in a prolonged crystallization time. The glacial acetic acid also ensures a protonated carboxyl group. Neat grinding or the LAG synthesis with water as well as precipitation reaction lead to an amorphous product. The amorphous products have been characterized by IR- and Raman-spectroscopy (Fig. S2, S3)

The synthesis of a cerium(IV) bis(carboxymethylphosphonate) monohydrate from solution under ambient conditions, like the synthesis of $\mathbf{1}$, was not successful. Adding a phosphonoacetic acid solution to a CAN solution results in an immediate precipitation, but the separated and dried product shows no reflections in the PXRD analysis.

The in situ investigation of the precipitation reaction of $\mathbf{1}$ shows that the product is formed rapidly, but a complete crystallization needs more time. The life time of the detected intermediate is too short for an isolation. Based on the data, no suggestion of the nature of this compound can be made.

The in situ investigations of the mechanochemical reactions indicate that the addition of water increases the reaction speed drastically and also leads to a complete conversion. Only in the LAG synthesis the formation of an intermediate is observed. The reflections of this intermediate are not at the same positions as the reflections of the intermediate in the precipitation reaction, but they are in good agreement with the reflection positions of an unknown intermediate found earlier for the mechanochemical synthesis of metal phenylphosphonates with $\mathrm{Cu}[33], \mathrm{Co}[19,20]$ and $\mathrm{Ni}[22]$. Since the use of phenylphosphonic acid is the only common aspect in these reactions, the intermediate is probably a polymorphic form of this reactant.

In both syntheses compound $\mathbf{1}$ is formed very quickly, in the precipitation reaction even within the first second. In both reactions an unknown intermediate is formed. Because of the different reflection positions their nature is different, therefore the two syntheses have different pathways. The fast synthesis under mild conditions also ensure that the cerium(IV) remains in its oxidation state.

\section{Conclusion}

Two cerium(IV) phosphonates were synthesized in fast and facile procedures. Both compounds have layered structures with coordinating phosphonate groups and the organic part between the layers. The in situ investigations of the syntheses of $\mathrm{Ce}\left(\mathrm{O}_{3} \mathrm{PC}_{6} \mathrm{H}_{5}\right)_{2} 1$ reveal that the product is formed within the first seconds from solution and the first two minutes in the mechanochemical synthesis. In both pathways an unknown intermediate could be obtained. In the mechanochemical synthesis the intermediate is most probably a polymorphic phase of phenylphosphonic acid. The results show that the use of fast syntheses under mild conditions can easily lead to metal phosphonates containing cerium(IV). 


\section{Acknowledgements}

The authors are grateful for the funding received from the DFG program "Crystalline non-equilibrium compounds" (grant number Em198/3-2). Manuel Wilke has received funding from the European Union's Horizon 2020 research and innovation program under the Marie Skłodowska-Curie grant agreement No_701647.

\section{Compliance with ethical standards}

Conflict of interest: The authors declare that they have no conflict of interest.

\section{References}

[1] Chen Z, Zhou Y, Weng L, Yuan C, Zhao D (2007) A zeolite-like zinc phosphonocarboxylate framework and its transformation into two- and three-dimensional structures. Chem- Asian J 2:1549-1554

[2] Miller SR, Pearce GM, Wright PA, Bonino F, Chavan S, Bordiga S, Margiolaki I, Guillou N, Feerey G, Bourrelly S, Llewellyn PL (2008) Structural transformations and adsorption of fuelrelated gases of a structurally responsive nickel phosphonate metal-organic framework, $\mathrm{Ni}$ STA-12. J Am Chem Soc 130 (47):15967-15981

[3] Dutta A, Patra AK, Bhaumik A (2012) Porous organic-inorganic hybrid nickel phosphonate: Adsorption and catalytic applications. Microporous Mesoporous Mater 155:208-214

[4] Liu YP, Guo SX, Bond AM, Zhang J, Du SW (2013) Cobalt(II) phosphonate coordination polymers: Synthesis, characterization and application as oxygen evolution electrocatalysts in aqueous media and water-saturated hydrophobic 1-butyl-3-methylimidazolium hexafluorophosphate ionic liquid. Electrochim Acta 101:201-208

[5] Sen R, Saha D, Mal D, Brandao P, Rogez G, Lin Z (2013) Synthesis, Structural Aspects and Catalytic Performance of a Tetrahedral Cobalt Phosphonate Framework. Eur J Inorg Chem 2013 (28):5020-5026

[6] Alberti G, Casciola M, Palombari R, Peraio A (1992) Protonic conductivity of layered zirconium phosphonates containing-SO3H groups. II. AC conductivity of zirconium alkyl sulfophenyl phosphonates in the range $100-200^{\circ} \mathrm{C}$, in the presence or absence of watervapor. Solid State lonics 58 (3-4):339-344

[7] Taylor JM, Mah RK, Moudrakovski IL, Ratcliffe Cl, Vaidhyanathan R, Shimizu GKH (2010) Facile Proton Conduction via Ordered Water Molecules in a Phosphonate Metal-Organic Framework. J Am Chem Soc 132 (40):14055-14057

[8] Thakkar R, Chudasama U (2010) Synthesis, Characterization and Proton Transport Properties of Mixed Metal Phosphonate-Zirconium Titanium Hydroxy Ethylidene Diphosphonate. J Iran Chem Soc 7 (1):202-209

[9] Bazaga-Garcia M, Papadaki M, Colodrero RMP, Olivera-Pastor P, Losilla ER, Nieto-Ortega B, Aranda MAG, Choquesillo-Lazarte D, Cabeza A, Demadis KD (2015) Tuning Proton Conductivity in Alkali Metal Phosphonocarboxylates by Cation Size-Induced and WaterFacilitated Proton Transfer Pathways. Chem Mater 27 (2):424-435

[10] Cai ZS, Bao SS, Wang XZ, Hu Z, Zheng LM (2016) Multiple-Step Humidity-Induced SingleCrystal to Single-Crystal Transformations of a Cobalt Phosphonate: Structural and Proton Conductivity Studies. Inorg Chem 55 (7):3706-3712

[11] Demadis KD, Stavgianoudaki N (2012) Chapter 14 Structural Diversity in Metal Phosphonate Frameworks: Impact on Applications. In: Metal Phosphonate Chemistry: From Synthesis to Applications. The Royal Society of Chemistry, pp 438-492 
[12] Goura J, Chandrasekhar V (2015) Molecular Metal Phosphonates. Chem Rev 115 (14):68546965

[13] Zheng Y-Z, Zhou G-J, Zheng Z, Winpenny REP (2014) Molecule-based magnetic coolers. Chem Soc Rev 43 (5):1462-1475

[14] Ma KR, Kan YH, Wang XL, Cao L (2016) Three Metal(II) Diphosphonates with d(10) Electron Configuration: Structural, Fluorescent and Electrochemical Studies. J Cluster Sci 27 (1):213226

[15] Zhu Y-P, Ma T-Y, Liu Y-L, Ren T-Z, Yuan Z-Y (2014) Metal phosphonate hybrid materials: from densely layered to hierarchically nanoporous structures. Inorg Chem Front 1 (5):360-383

[16] Bauer S, Bein T, Stock N (2005) High-throughput investigation and characterization of cobalt carboxy phosphonates. Inorg Chem 44 (16):5882-5889

[17] Bauer S, Stock N (2007) Implementation of a temperature-gradient reactor system for highthroughput investigation of phosphonate-based inorganic-organic hybrid compounds. Angew Chem Int Ed 46 (36):6857-6860

[18] Schilling LH, Stock N (2014) High-throughput ultrasonic synthesis and in situ crystallisation investigation of metal phosphonocarboxylates. Dalton Trans 43 (2):414-422

[19] Wilke M, Bach S, Gorelik Tatiana E, Kolb U, Tremel W, Emmerling F (2017) Divalent metal phosphonates - new aspects for syntheses, in situ characterization and structure solution. Zeitschrift für Kristallographie - Crystalline Materials232 (1-3):209-222

[20] Batzdorf L, Fischer F, Wilke M, Wenzel KJ, Emmerling F (2015) Direct In Situ Investigation of Milling Reactions Using Combined X-ray Diffraction and Raman Spectroscopy. Angew Chem Int Ed 54 (6):1799-1802

[21] Wilke M, Batzdorf L, Fischer F, Rademann K, Emmerling F (2016) Cadmium phenylphosphonates: preparation, characterisation and in situ investigation. Rsc Advances 6 (42):36011-36019

[22] Wilke M, Buzanich AG, Reinholz U, Rademann K, Emmerling F (2016) The structure and in situ synthesis investigation of isomorphic mononuclear molecular metal phenylphosphonates. Dalton Trans 45 (23):9460-9467

[23] I. Halasz, A. Puskaric, S. A. J. Kimber, P. J. Beldon, A. M. Belenguer, F. Adams, V. Honkimaki, R. E. Dinnebier, B. Patel,W. Jones, V. Strukil, T. Friščić (2013) Real-Time In Situ Powder X-ray Diffraction Monitoring of Mechanochemical Synthesis of Pharmaceutical Cocrystals. Angew. Chem. Int. Ed. 52 (44):11538 - 11541; Angew. Chem. 125 (45), 11752 - 11755

[24] I. Halasz, S. A. J. Kimber, P. J. Beldon, A. M. Belenguer, F. Adams, V. Honkimaki, R. C. Nightingale, R. E. Dinnebier, T. Friščić (2013) In situ and real-time monitoring of mechanochemical milling reactions using synchrotron X-ray diffraction. Nat. Protoc. 8:1718 $-1729$

[25] D. Gracin, V. Strukil, T. Friščić, I. Halasz, K. Uzarevic (2014) Laboratory Real-Time and In Situ Monitoring of Mechanochemical Milling Reactions by Raman Spectroscopy. Angew. Chem. Int. Ed. 53 (24):6193 - 6197; Angew. Chem. 126 (24):6307-6311[26] Alberti G, Costantino U, Allulli S, Tomassini N (1978) Crystalline ZR(R-PO3)2 and ZR(R-OPO3)2 compounds ( $R=$ organic radical) - a new class of materials having layered structure of the zirconiumphosphate type. J Inorg Nucl Chem 40 (6):1113-1117

[27] Clearfield A (1996) Recent advances in metal phosphonate chemistry. Curr Opin Solid State Mater Sci 1 (2):268-278

[28] Clearfield A (2008) Unconventional metal organic frameworks: porous cross-linked phosphonates. Dalton Trans (44):6089-6102

[29] Pica M, Donnadio A, D'Amato R, Capitani D, Taddei M, Casciola M (2014) Layered metal(IV) phosphonates with rigid pendant groups: New synthetic approaches to nanosized zirconium phosphate phenylphosphonates. Inorg Chem 53 (4):2222-2229

[30] Juan DW, Good JJ, DiStefano VH, Albrecht-Schmitt TE (2011) Self-assembly of hexanuclear clusters of $4 f$ and $5 f$ elements with cation specificity. Eur J Inorg Chem (9):1374-1377 
[31] Diwu JA, Wang SA, Liao ZL, Burns PC, Albrecht-Schmitt TE (2010) Cerium(IV), neptunium(IV), and plutonium(IV) 1,2-phenylenediphosphonates: Correlations and differences between early transuranium elements and their proposed surrogates. Inorg Chem 49 (21):1007410080

[32] Costantino F, Gentili PL, Audebrand N (2009) A new dual luminescent pillared cerium(IV)sulfate-diphosphonate. Inorg Chem Commun 12 (5):406-408

[33] Costantino F, lenco A, Gentili PL, Presciutti F (2010) Synthesis, X-ray powder structure, and photophysical properties of three new ce(III) sulfate-diaminotetraphosphonate-based coordination polymers. Cryst Growth Des 10 (11):4831-4838

[34] Paris O, Li CH, Siegel S, Weseloh G, Emmerling F, Riesemeier H, Erko A, Fratzl P (2007) A new experimental station for simultaneous $X$-ray microbeam scanning for small- and wide-angle scattering and fluorescence at BESSY II. J Appl Crystallogr 40:S466-S470

[35] Hammersley AP, Svensson SO, Hanfland M, Fitch AN, Hausermann D (1996) Two-dimensional detector software: From real detector to idealised image or two-theta scan. High Pressure Res 14 (4-6):235-248

[36] Wilke M, Kabelitz A, Gorelik TE, Buzanich AG, Reinholz U, Kolb U, Rademann K, Emmerling F (2016) The crystallisation of copper(ii) phenylphosphonates. Dalton Trans 45 (43):1745317463

[37] David W I F, Shankland K, van de Streek J, Pidcock E, Motherwell W D S, Cole J C (2006) DASH: A program for crystal structure determination from powder diffraction data. J Appl Crystallogr 39:910-915

[38] Langford J I, Louer D (1996) Powder diffraction. Rep Prog Phys 59:131-234 